\title{
A Hydro PV Hybrid System for the Laranjeiras Dam (in Southern Brazil) Operating with Storage Capacity in the Water Reservoir
}

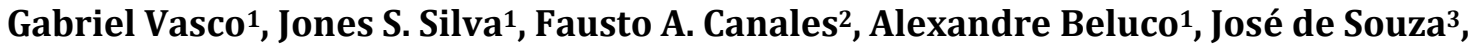 \\ Elton G. Rossini ${ }^{4}$ \\ ${ }^{1}$ Instituto de Pesquisas Hidráulicas, Universidade Federal do Rio Grande do Sul, Porto Alegre, Brazil \\ ${ }^{2}$ Departamento de Ingeniería Civil y Ambiental, Universidad de la Costa, Barranquilla, Colombia \\ ${ }^{3}$ Fundação Liberato Salzano Vieira da Cunha, Novo Hamburgo, Brazil \\ ${ }^{4}$ Universidade Estadual do Rio Grande do Sul, Porto Alegre, Brazil \\ Email: albeluco@iph.ufrgs.br
}

How to cite this paper: Vasco, G., Silva, J.S., Canales, F.A., Beluco, A., de Souza, J. and Rossini, E.G. (2019) A Hydro PV Hybrid System for the Laranjeiras Dam (in Southern Brazil) Operating with Storage Capacity in the Water Reservoir. Smart Grid and Renewable Energy, 10, 83-97. https://doi.org/10.4236/sgre.2019.104006

Received: January 3, 2019

Accepted: April 25, 2019

Published: April 28, 2019

Copyright (๑) 2019 by author(s) and Scientific Research Publishing Inc. This work is licensed under the Creative Commons Attribution International License (CC BY 4.0).

http://creativecommons.org/licenses/by/4.0/

\begin{abstract}
Seasonal variability coupled with the intermittency of renewable energy sources makes reservoir hydroelectric plants an interesting option to consider in hybrid energy systems, especially in cases of dams that have not been completed or have been abandoned and which still have some potential for reuse. The Laranjeiras dam was completed in the 1960s and the original project for hydroelectric power generation was not completed, made impossible by economic changes during the construction years. A recent study proposed the implementation of a hydroelectric photovoltaic hybrid system with lower horsepower to allow the dam to be made useful again. This paper presents the results of the computational simulations with the software Homer, considering the operation of the hydroelectric component (of the proposed hybrid system) with reservoir, playing the role of energy storage device when the production exceeds the demand at a given moment, reducing the loss of energy due to unavailability of demand. The study suggested to implement a hydroelectric power plant with power house at the base of the dam that has a height of $20 \mathrm{~m}$, operating at a minimum flow of $9171 \mathrm{~L} / \mathrm{s}$, with reservoir operating as a device for energy storage, operating with a photovoltaic system of $360 \mathrm{~kW}$, and a power limit for the purchase of energy from the grid equal to $200 \mathrm{~kW}$, providing consumer loads up to $40 \mathrm{MWh}$ per day, with cost of energy equal to US $\$ 0.021$ per $\mathrm{kWh}$ and a capital cost of US\$3285.617.
\end{abstract}

\section{Keywords}

Hybrid Systems, Energetic Complementarity, PV Modules on Floating 
Structures, Pre Feasibility Study, Software Homer

\section{Introduction}

Renewable resources are an important alternative for obtaining energy supplies, both on a small scale and by considering the larger interconnected systems. However, energy resources have some characteristics that make it difficult to use them, such as their unpredictable availability or their availability profile, which is almost always different from consumer demand profiles [1] [2]. One way to overcome these difficulties is the adoption of energy storage, allowing accumulation of excess energy for use in times of drought. Unfortunately, there are still no really efficient ways to store energy after the process of converting other forms of energy into electricity.

In this sense, the use of water reservoirs is the most efficient means currently available for energy storage and Brazil has a privileged situation, due to its great availability of water resources. Brazil currently operates a large number of reservoirs and the country is currently experiencing a crisis of water availability, which creates an environment of possible energy rationing and uncertainties as to the best ways to expand the energy system. This article intends to collaborate in this scenario with a study to add elements to the process of repowering an abandoned dam, which has lost viability over the years of its construction, with the economic crises experienced by Brazil in recent decades.

Canales, Beluco and Mendes [3] have recently published a study comparing the operation of a hydroelectric plant with a reservoir and a reversible plant in the same enterprise, concluding that this second configuration proved to be better from the technological point of view and also had the lowest environmental impacts. This study was based on the use of the well-known software Homer in its Legacy version [4] [5], which simulates only hydroelectric power plants operating at an instantaneous flow rate. This study was possible because, previously, a method to simulate hydroelectric power plants operating with reservoirs with capacity for energy storage [6] was developed. A method to simulate reversible hydroelectric plants [7] has also been developed.

The Laranjeiras dam in southern Brazil was built in the 1960s but its energy project has lost viability over the years, with successive economic crises experienced by Brazil. The original project aimed to extract almost $7 \mathrm{MW}$ of a structure that had a reservoir with 200,000 cubic meters and a channel with 5900 meters long. Only the dam was completed and over time it found tourist purposes, being used to create favorable conditions for rafting. A recent study [8] proposed the implementation of a hydroelectric photovoltaic hybrid system to enable repowering of the dam. The proposed system was based on a hydroelectric power plant with $1497 \mathrm{~kW}$ installed at the base of the dam and a set of $180 \mathrm{~kW}$ on photovoltaic panels installed on the surface of the reservoir. 
Yüksel [9] emphasizes that the existence of a reservoir in a hydroelectric plant allows hydroelectric power to be adaptable and flexible because the generation of electric energy can be programmed and optimized. Hydropower reservoirs can significantly increase the efficiency of hybrid power systems by reducing pollutant emissions and enabling better integration of renewable sources such as wind or solar energy. The construction of dams and the operation of water reservoirs have several positive and negative impacts on the environment and, more broadly, on the societies in which they are inserted, as discussed by Zhang et al. [10]. In this way, it is very positive that reservoirs representing potential for power generation have this potential properly explored.

This paper intends to contribute to studies involving the generation of energy in hybrid systems of micro and small size, eventually taking advantage of the complementarity between energy sources, in which the use of some energy storage device can result in reduction of the cost of energy. In this sense, this paper presents a case study in which clearly a reservoir used for energy storage contributes to improve the performance of a photovoltaic hydroelectric hybrid system.

This paper presents a study for the use of the reservoir formed by the Laranjeiras dam for energy storage to improve the performance of the hybrid photovoltaic hydroelectric system proposed for repowering the use of the dam. The study is based on the use of Homer software, applying specific method [6] for simulation of hydroelectric plants with reservoir. This article is composed of five other sections besides this Introduction. The next section describes the system under study and the following section presents the simulation of reservoir hydroelectric plants. The two subsequent sections present respectively the simulations performed with Homer and the discussion of the results. The last section ends the article listing the conclusions.

\section{Hydro PV Hybrid System under Study}

Figure 1 shows the schematic diagram of the model adopted to describe the hydroelectric photovoltaic hybrid system proposed in this study. The hybrid system simulated with Homer includes hydroelectric power plant with reservoir operated as energy storage, simulated following the method proposed by Canales, Beluco and Mendes [6], with photovoltaic panels and with the possibility of buying and selling energy to the grid. The hydroelectric plant appears connected to the DC bus, with the reservoir simulated by a battery, with the DC bus having only these components connected. The photovoltaic panels, as a consequence, appear connected to the AC bus.

The optimum solution obtained with Homer software for the repowering of the Laranjeiras dam [8] includes a 20-meter-high hydroelectric power plant with an average flow of 9171 liters per second generating $1497 \mathrm{~kW}$ installed at the base of the dam, operating in conjunction with photovoltaic panels of $180 \mathrm{~kW}$, operating on floating structures on the reservoir surface. This system was simulated with the possibility of buying and selling $400 \mathrm{~kW}$ for the grid, providing 40 
MWh per day, with a capital cost of US $\$ 3,984,885.00$ per $\mathrm{kW}$ and cost of energy equal to US $\$ 0.026$ per $\mathrm{kWh}$.

Figure 2 (reproduced from Ref. [8]) shows the Laranjeiras dam and a portion of the reservoir near the dam. This region can be found on Google Maps at the following link: https://goo.gl/maps/E8WuBzWMmpv. In this figure, just above the dam, a diagram showing 18 squares appears to compare the dimensions of a set of floating structures for photovoltaic panels with the dimensions of the region near the dam. Each of these squares corresponds to a $30 \mathrm{~kW}$ structure of photovoltaic panels. Thus, the optimum solution described above corresponds to one-third of the area occupied by these 18 squares in the figure.

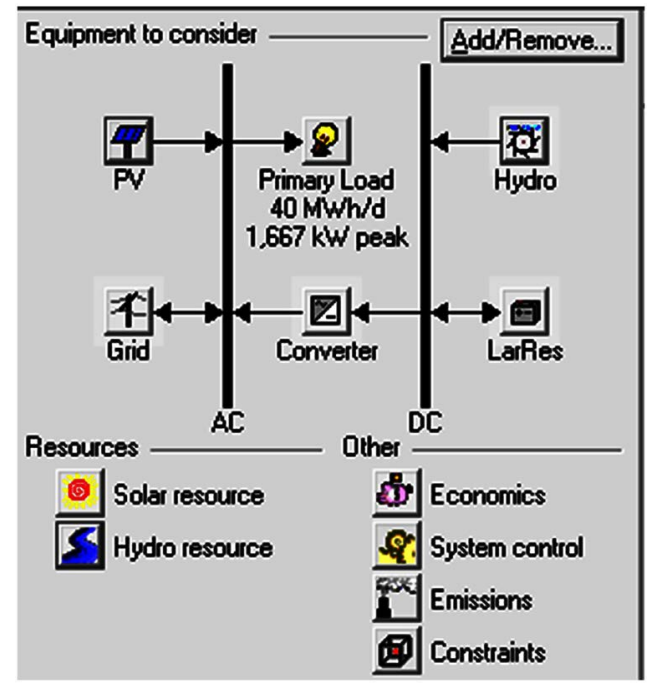

Figure 1. Schematic diagram of the model for the hydro PV hybrid system proposed in this study.

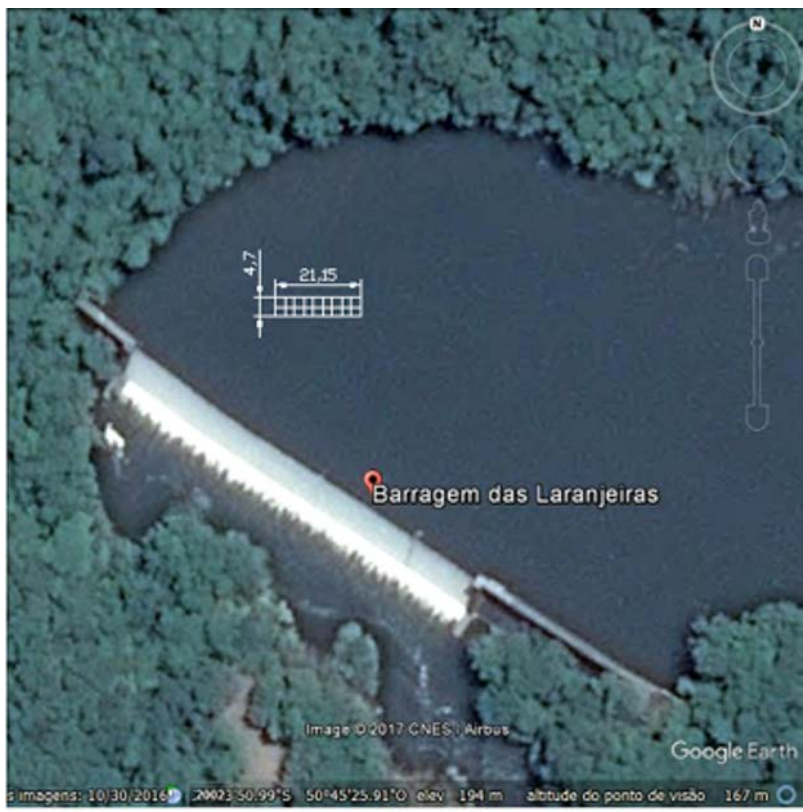

Figure 2. Image of the Laranjeiras Dam. 
The use of photovoltaic panels on the surface of reservoirs can have a number of advantages beyond the energy issue [11]. In this case, however, occupying such a small probable area, these advantages all vanish from the mere supply of energy. Wide photovoltaic coverage can help reduce water evaporation (reducing the loss of accumulated water) and reduce algae formation (with possible problems in turbine operation).

\section{Simulation of the Reservoir with Storage Capacity}

This study intends to evaluate the operation of a hydro PV hybrid system in the Laranjeiras dam using the possible storage capacity of the reservoir to obtain a better performance in the energy supply. In this sense, the software Homer will be used to study the consequences of energy storage on the performance of the hydro PV hybrid system. Following suggestions from Canales, Beluco and Mendes [6], the reservoir will be simulated using the model used by Homer to describe batteries.

Figure 3 shows the accumulated volumes and the areas occupied by the reservoir formed by the Laranjeiras dam as a function of heights above sea level. The $212.00 \mathrm{~m}$ level corresponds to the top level of the dam. The $210.00 \mathrm{~m}$ level is considered the normal level and the daily variation is $1.40 \mathrm{~m}$, between levels $211.00 \mathrm{~m}$ and $208.60 \mathrm{~m}$. The information on volume as a function of relative height will be used to transform a model of battery into a model of a reservoir of hydroelectric power plant.

Figure 4 shows the data used to reconfigure the model of a 6FM200D battery to describe the performance of a water reservoir with the characteristics of the reservoir formed by the Laranjeiras dam. Unlike a real rechargeable battery, the reservoir will not lose charge for issues related to chemical reactions, but water may be lost through evaporation. Also unlike a real battery, the reservoir will not have its charging and recharging capacity changed if deep discharges occur, resulting in very low states of charge.

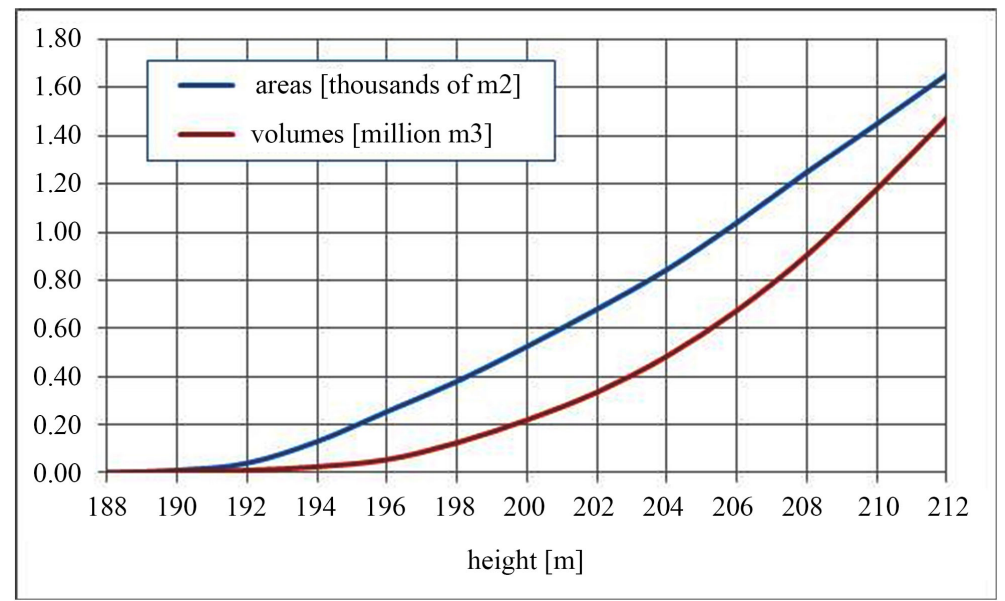

Figure 3. Relationship between dimensions and areas and between dimensions and volumes for the reservoir formed by the Laranjeiras dam. 


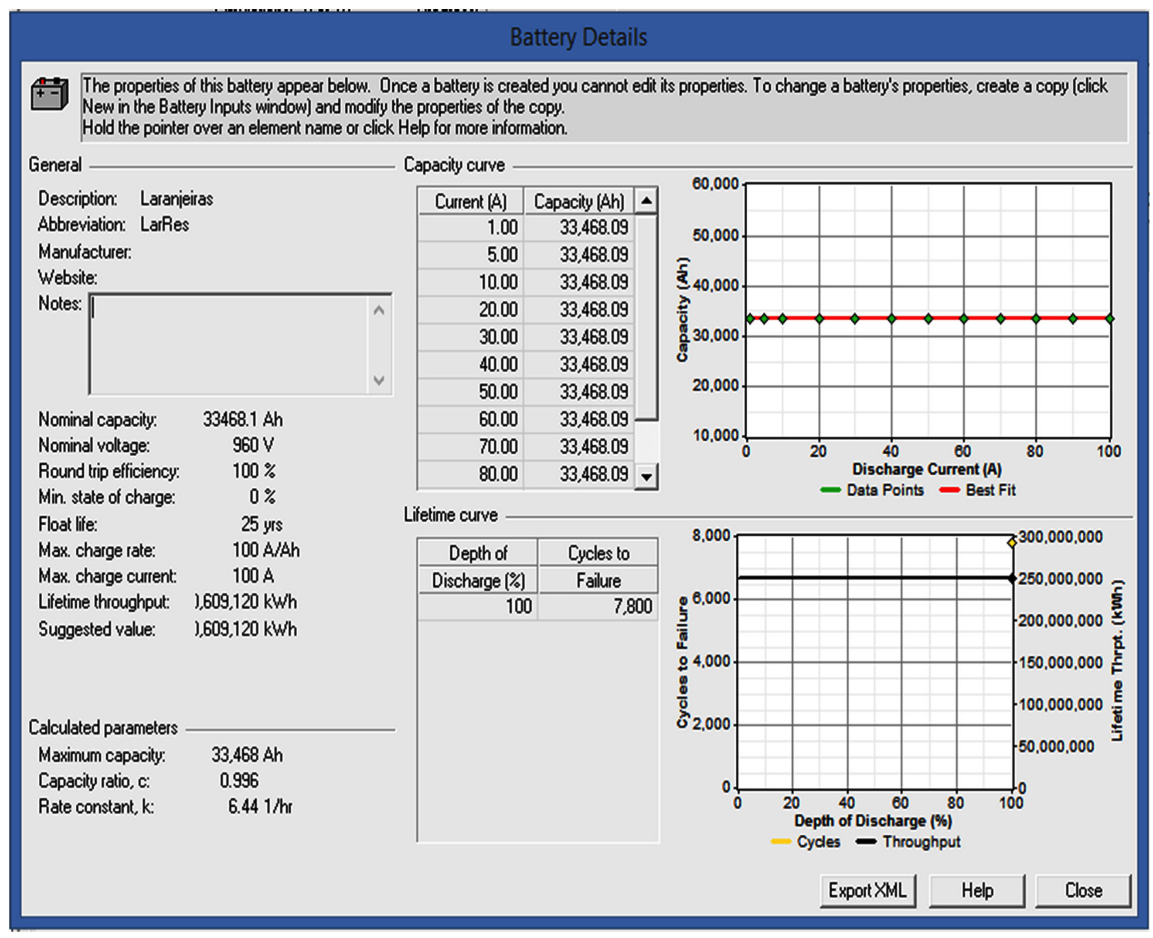

Figure 4. Use of the battery as a model to describe the reservoir formed by the Laranjeiras Dam.

The model adopted for the simulations of this study, however, is much simpler than the model proposed by Canales, Beluco and Mendes [6] from the model of a 6FM200D [12] automotive battery. The battery has a nominal capacity of $33,468 \mathrm{Ah}$ with a voltage equal to 960 Volts, resulting in a total storage capacity of $32,130 \mathrm{kWh}$ (equivalent to the total energy stored in the reservoir). The battery has an efficiency of $100 \%$, maximum charge rate equal to 100 Ampèresper Ah, maximum load current equal to 100 Ampères, for an operating period of 25 years. The parameters of the model are maximum capacity of $33,468 \mathrm{Ah}$, capacity ratio of 0.996 and rate constant equal to 6.44 per hour.

\section{Simulations with Homer}

Homer [4] [5] is a well-known software [13] allowing the simulation of micro and small hybrid systems based on renewable energy resources, with support of diesel systems, connected to the grid and with energy storage in some types of batteries and also including the possibility of working with hydrogen. Homer simulates the hybrid system for all combinations of optimization variables, thus constructing an optimization space, identifying in this space the effects of sensitivity variables. The Legacy version [14] was used in this work, but there are new versions available on the Homer Energy website.

Figure 1 shows the diagram of the simulated system in this study, which corresponds to the system of the work of Vasco et al. [8], now including the water reservoir as a device for energy storage. The figure shows a hydro PV hybrid system with connection to the grid intending to initially meet the same load 
served by the system simulated by Vasco et al. [8], with 40 MWh of daily consumption with constant demand of $1667 \mathrm{~kW}$.

Figure 5 shows the water availability data, which was obtained with the discharge data of the plant upstream in the same river. In this figure, above, monthly minimum, average and maximum values and below, the hourly distribution of the stream flow throughout the year. In addition to the water availability data, cost data are also required for system simulation. The cost of repowering project, including the purchase of components and installation of hydroelectric power plant was estimated in 2010 as being in the range of US\$500.00 to US $\$ 1000.00$ per $\mathrm{kW}$ installed in Brazil [15]. According to Braciani [16], the average cost per kilowatt installed from reservoir hydroelectric in Brazil is about US $\$ 1324.00$ per $\mathrm{kW}$, with approximately $45 \%$ of this cost corresponding to civil works.

The configuration proposed by Vasco et al. [8] suggests the installation of the engine room of the hydroelectric plant along the base of the dam, according to the topography of the terrain. The turbine can operate with flows from $50 \%$ to $150 \%$ of the nominal flow rate, which is equal to 9000 liters per second and the height of the hydroelectric potential is 20 meters, resulting in an installed power of $1497 \mathrm{~kW}$. Simulations with Homer were performed considering the stream flow as a sensitivity variable, with values scaled by $9171 \mathrm{~L} / \mathrm{s}, 10,088 \mathrm{~L} / \mathrm{s}$ and $11,005 \mathrm{~L} / \mathrm{s}$, corresponding respectively to the value suggested by the data of Figure 5 , and to the addition of $10 \%$ and $20 \%$ to this value. These increment values correspond to the flow of a contributing river, which was not added to the data of Figure 5, but whose maximum contribution was evaluated expeditiously.
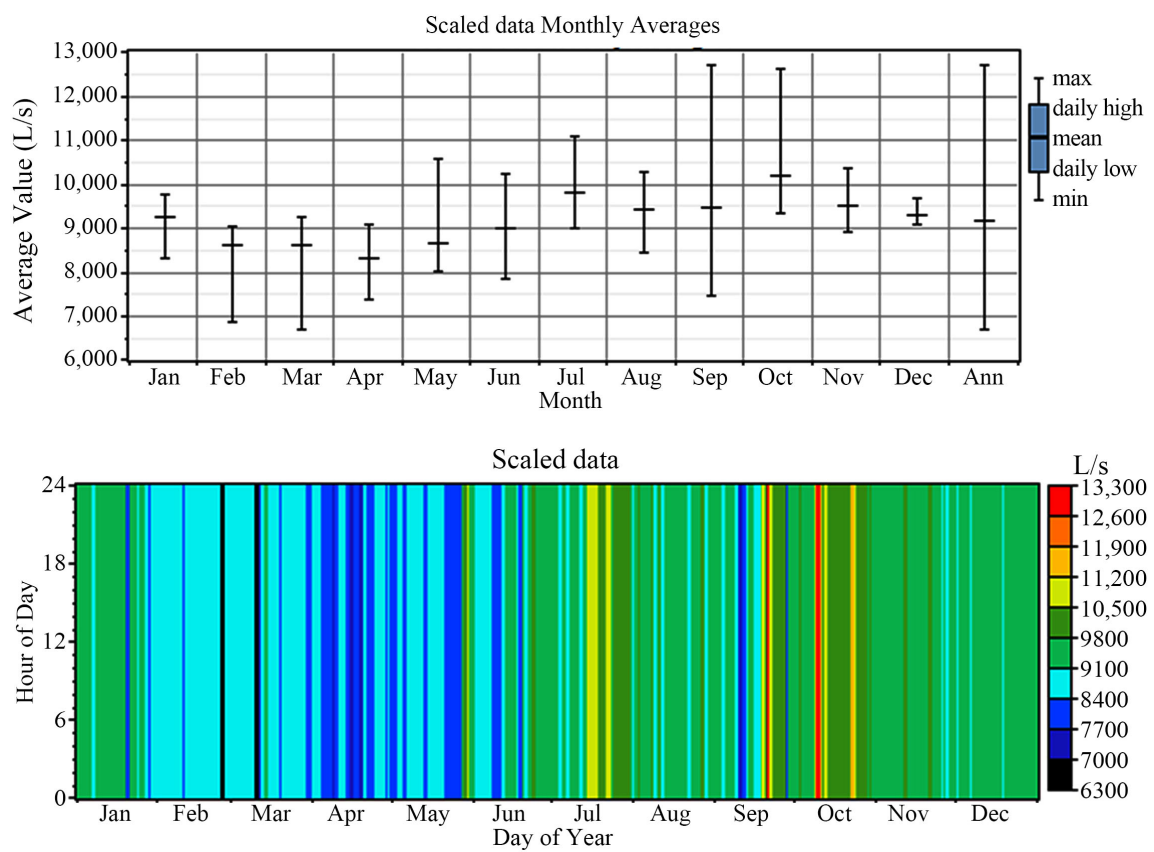

Figure 5. Flow discharged by the Canastra hydroelectric power plant. Above, monthly minimum, average and maximum values; below, the hourly distribution of the values throughout the year. 
The costs of the hydroelectric power plant are considered as a sensitivity variable to allow the analysis of its influence on the project, since it is a power plant to be reformulated. The capital cost as a sensitivity variable was considered in the simulations with the following values: US $\$ 750,000.00$ per $\mathrm{kW}$, US $\$ 900,000.00$ per $\mathrm{kW}$, US $\$ 1,050,000.00$ per $\mathrm{kW}$. The cost of replacing the equipment at the end of its useful life is considered to be equal to $80 \%$ of the capital cost. The annual cost of operation and maintenance has a typical value of $4 \%$ of the capital cost [15], resulting in US $\$ 37,500.00$ per $\mathrm{kW}$, US $\$ 450,000.00$ per $\mathrm{kW}$, US $\$ 52,500.00$ per $\mathrm{kW}$. These values for replacement costs and operation and maintenance costs are linked to the capital cost for the simulations.

Figure 6 shows the data of solar radiation incident on horizontal plane at the dam site, which were obtained by the software Homer [4] [5] in a NASA database. In this figure, above, monthly minimum, average and maximum values and below, the hourly distribution of the solar radiation throughout the year. The second of the two graphs in this figure is very eloquent as to the intermittence of solar energy throughout the days of the year, subject to the natural variation of the solar energy resource and the influence of the climate throughout the seasons. In addition to the solar resource data, cost data are also required for system simulation. Photovoltaic panels have at the same time presented a reduction of costs for acquisition and a pronounced growth in their demand for energy conversion facilities on several different scales.

The set of photovoltaic panels and floating structure with installed power of $30 \mathrm{~kW}$, as suggested by Schultz [17], was used as reference. The size of the photovoltaic system was considered in the simulations as optimization variables, with the following values: $0 \mathrm{~kW}, 180 \mathrm{~kW}, 360 \mathrm{~kW}, 540 \mathrm{~kW}, 720 \mathrm{~kW}, 900 \mathrm{~kW}$, $1080 \mathrm{~kW}, 1260 \mathrm{~kW}, 1440 \mathrm{~kW}$, always multiples of $30 \mathrm{~kW}$. The useful life was considered as equal to 12.5 years, thus avoiding considerable losses of efficiency for a project period of 25 years.

The cost of purchasing photovoltaic panels was considered equal to US $\$ 3200$ per kWp, with an end-of-life cost of $80 \%$ of this value and an annual cost of operation and maintenance equal to $5 \%$ of the capital cost. The cost of set photovoltaic panels and supporting and floating structure adds approximately $30 \%$ to the capital cost of photovoltaic panels [11]. As photovoltaic plants have been receiving fiscal and financial incentives of various types, and have been experiencing a considerable reduction of acquisition costs with each new year, the simulations included as a sensitivity variable a multiplicative cost factor, with the following values: $1.00,0.50,0.25,0.15,0.10,0.05,0.01$.

The generators of the hybrid power system are interconnected by AC and DC busbars and are responsible for providing a constant electric charge to the grid. The flow of energy from one bar to the other is possible with the use of converters, which perform the functions of inverters and rectifiers in the same component. The device can function as rectifier and inverter with $100 \%$ of the total capacity, with efficiency of $85 \%$ as an inverter and $90 \%$ as a rectifier. The useful life is estimated as 12.5 years. 

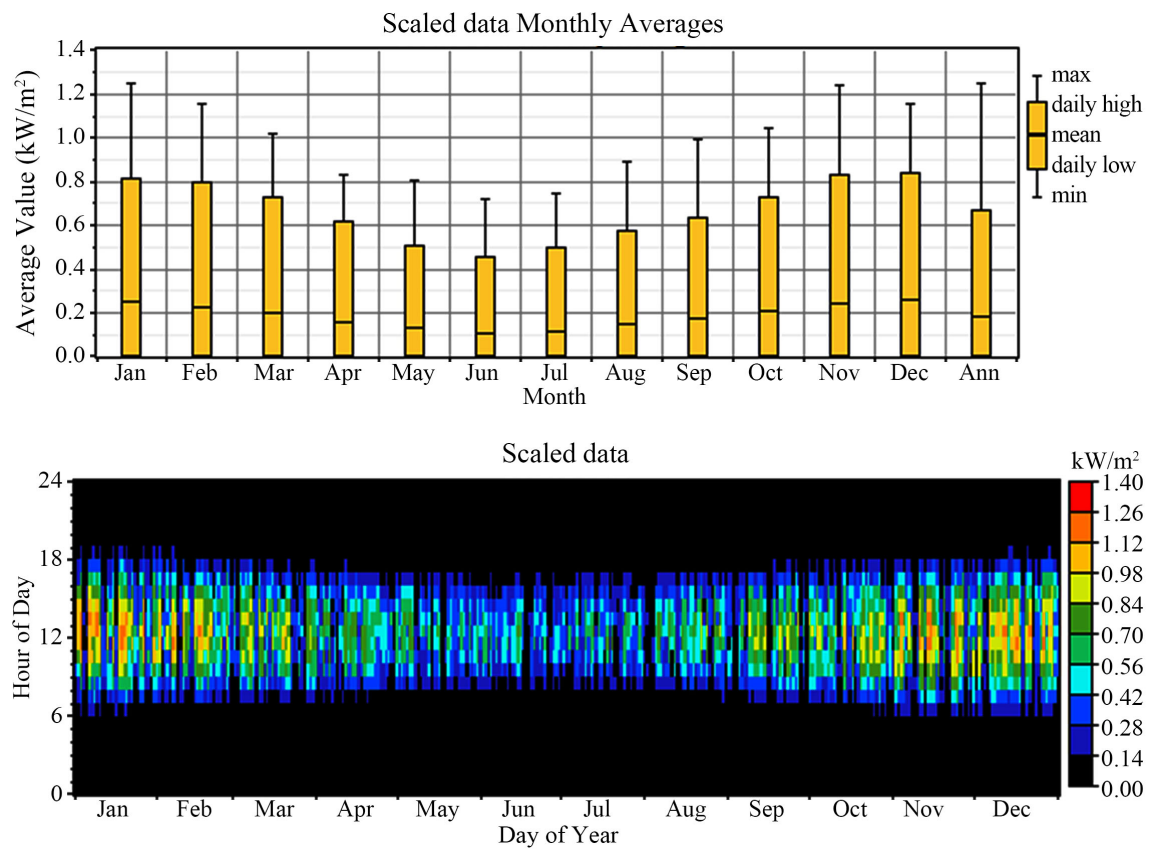

Figure 6. Solar radiation incident on a horizontal plane, obtained with HOMER, for the location of the Laranjeiras Dam. Power Plant. Above, monthly minimum, average and maximum values; below, the hourly distribution of the values throughout the year.

The system is also supported by a diesel generation system, inserted in the simulations with the following installed capacities: $0 \mathrm{~kW}, 12.5 \mathrm{~kW}$ and $25 \mathrm{~kW}$. The system also has batteries, inserted as banks of batteries with 0,60 and 120 batteries. The simulations were performed for the following values for the sensitivity variables: 30,000 MWh per day, 35,000 MWh per day and 40,000 MWh per day for the constant load of the energy system to be served; $0 \mathrm{~kW}, 200 \mathrm{~kW}$ and 400 $\mathrm{kW}$ for the power purchase and sale capacity of the grid; and US $\$ 0.60$ per liter, US $\$ 0.70$ per liter, US $\$ 0.80$ per liter and US $\$ 0.90$ per liter of diesel.

Table 1 presents the optimization variables while Table 2 shows the sensitivity variables considered in the simulations performed with the Homer Legacy. The 27 variables, 9 to 9 , in the last three columns of Table 2, actually count as 9 variables, 3 to 3 , since the variables are linked as indicated.

\section{Results and Discussion}

This chapter presents the results of the simulation of the hybrid system shown in Figure 1, which is basically the system simulated by Vasco et al. [8], now with the photovoltaic modules in the AC bus and the DC bus dedicated to the simulation of the hydroelectric power plant proposed by them and operated with the use of the energy storage capacity provided by the reservoir formed by the Laranjeiras dam. The system proposed by Vasco et al. [8] basically included a hydroelectric plant with $1497 \mathrm{~kW}$ and a set of photovoltaic panels (on floating structures installed on the water surface) with $180 \mathrm{~kW}$, meeting a constant demand of the grid of $1667 \mathrm{~kW}$ and $40 \mathrm{MWh}$ per day. 
Table 1. Optimization variables for the simulations performed with Homer Legacy.

\begin{tabular}{ccccc}
\hline \multicolumn{2}{c}{ PV array $[\mathrm{kW}]$} & Grid $[\mathrm{kW}]$ & Lar Res & Converter $[\mathrm{kW}]$ \\
\hline 0.0 & 900.0 & 0.0 & 0 & 0.0 \\
180.0 & 1080.0 & 200.0 & 1 & 1800.0 \\
360.0 & 1260.0 & 400.0 & 2 & 3600.0 \\
540.0 & 1440.0 & & 3 & 5400.0 \\
720.0 & & & 4 & 7200.0 \\
\hline
\end{tabular}

Table 2. Sensitivity variables for the simulations performed with Homer Legacy.

\begin{tabular}{ccccc}
\hline $\begin{array}{c}\text { Primary load } \\
{[\mathrm{kWh} / \mathrm{d}]}\end{array}$ & $\begin{array}{c}\text { Stream } \\
\text { Flow }[\mathrm{L} / \mathrm{s}]\end{array}$ & $\begin{array}{c}\text { Hydro } \\
\text { Capital }[\$]\end{array}$ & $\begin{array}{c}\text { LarRes Capital } \\
\text { Multiplier }\end{array}$ & $\begin{array}{c}\text { Converter Capital } \\
\text { Multiplier }\end{array}$ \\
\hline $30,000.0$ & 9171.0 & $250,000.00$ & 1.00 & 1.00 \\
$35,000.0$ & $10,088.1$ & $300,000.00$ & 1.20 & 1.20 \\
$40,000.0$ & $11,005.2$ & $350,000.00$ & 1.40 & 1.40 \\
$45,000.0$ & & linked to & linked to & linked to \\
& Hydro Repl [\$] & LaRes Repl Multiplier & $\begin{array}{c}\text { Converter Repl. } \\
\text { Multiplier }\end{array}$ \\
& $200,000.00$ & 1.00 & 1.00 \\
& $240,000.00$ & 1.20 & 1.20 \\
& $280,000.00$ & 1.40 & 1.40 \\
& linked to & linked to & linked to \\
& & & Converter O\&M \\
& & Hydro O\&M [\$] & LarRes O\&M Multiplier & Multiplier \\
& & $12,500.00$ & 1.00 & 1.00 \\
& $15,000.00$ & 1.40 & 1.20 \\
& $17,500.00$ & & 1.40 \\
& & &
\end{tabular}

Figure 7 shows the result provided by Homer and was considered the optimal result, indicating that the operation of the reservoir allows to increase the installed power in photovoltaic modules. The system proposed in this paper includes the hydroelectric power plant with $1497 \mathrm{~kW}$ and a set of photovoltaic panels (on floating structures installed on the water surface) with $360 \mathrm{~kW}$, meeting the same constant demand of the grid equal to $1667 \mathrm{~kW}$ and $40 \mathrm{MWh}$ per day. This system also considers the hydroelectric power plant operating with a stream flow rate obtained by the use of the energy storage capacity of the reservoir formed by the Laranjeiras dam.

The power appearing in "Conv" in (the ninth column of) this figure, equal to $1800 \mathrm{~kW}$, does not correspond to a power actually installed. This value was selected by Homer for the converter capacity and corresponds to the maximum power value that is inserted by the hydroelectric power plant operated with reservoir in the AC bus. This value is within the operating range of the hydroelectric plant, which is $1.497 \mathrm{~kW} \pm 748 \mathrm{~kW}$, corresponding to a range from $50 \%$ to $150 \%$ of the nominal flow rate. 


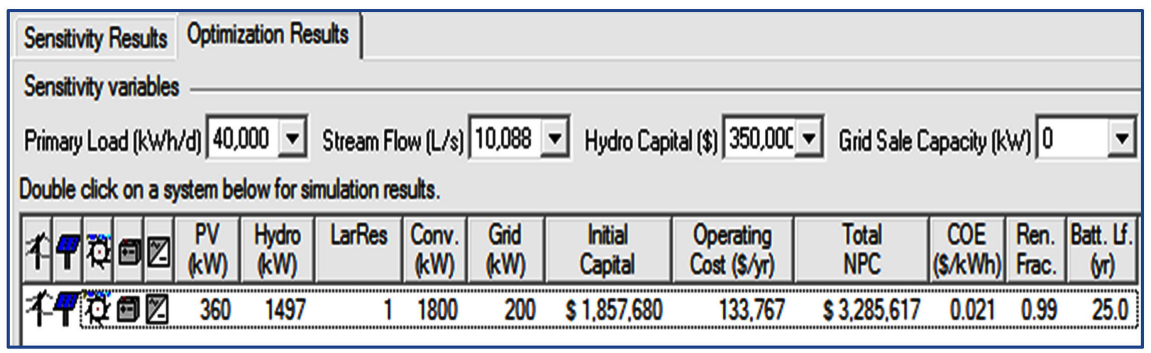

Figure 7. Optimal result obtained by Homer for the system of Figure 1.

The operation of the reservoir allowed to reduce the demand for energy supply from the grid to support some moments throughout the year, in which the available power was not sufficient to supply the consumers demand, from $400 \mathrm{~kW}$ [8] to $200 \mathrm{~kW}$. On the other hand, however, there is no surplus energy to be sold to the grid (affecting the viability of the system), in addition to the energy supply for which the system was designed, and thus the sales capacity for the grid is equal to $0 \mathrm{~kW}$.

The solution shown in Figure 7 presents a total net present cost of US $\$ 3,285,617$ and a capital cost of US $\$ 1,857,680$, with a cost of energy equal to US $\$ 0.021$ per $\mathrm{kWh}$, with $99 \%$ of the energy supplied to the hybrid system with renewable origin. These results should be quoted with the results presented by Vasco et al. [8], when this system was studied without the use of the reservoir as a device for energy storage. That system presented total net present cost of US $\$ 3,984,885$, capital cost of US\$1,154,480, cost of energy of US $\$ 0.026$ per $\mathrm{kWh}$ and $90 \%$ of the energy supplied with renewable origin, but with half the power installed in PV modules and with a capacity of storage in batteries much smaller than the capacity of storage of the reservoir. The hybrid system proposed in this paper presents lower total net present cost and greater penetration of renewable resources in the energy supply, losing only in the initial cost, since the use of the reservoir for energy storage allows the installation of a greater PV power.

Figure 8, Figure 9 and Figure 10 show optimization spaces for the capital cost of the hydroelectric power plant [US\$/kW] as a function of the consumers demand per day $[\mathrm{kWh} / \mathrm{d}]$, with the PV power superimposed on the graph, without connection to the grid, respectively for stream flow rates of $9171 \mathrm{~L} / \mathrm{s}$, 10,088 L/s and 11,005 L/s. The blank area in Figure 8 and Figure 9 indicate that no viable hybrid systems exist for these combinations of hydropower capital costs and consumers demand, caused by the reduction of the possibilities of buying and selling energy with the grid.

These three figures show only two possible solutions: in the first, the hydroelectric power plant only, in blue with sloping lines, while in the second, the hydroelectric power plant added to the photovoltaic modules, in yellow with sloping lines, both connected to the grid and with the water reservoir used for energy storage.

The results of Figure 9 indicate that the demand of $40 \mathrm{MWh}$ per day can be met with $360 \mathrm{~kW}$ in photovoltaic panels, but Figure 10, with the highest availa- 
ble flow, indicates that for the same demand the solutions do not include photovoltaic panels, but the demand of $45 \mathrm{MWh}$ per day should include a much higher power of $1440 \mathrm{~kW}$. These solutions meanwhile cost much more than other solutions, with a total net present cost of US\$8,203,995 and a cost of energy of US\$0.047 per kWh.

The solution adopted in this paper corresponds to an average stream flow greater rate than the average stream flow rate adopted in the solution proposed by Vasco et al. [8], without the use of the reservoir for energy storage. The higher average flow rate, equal to $10,088 \mathrm{~L} / \mathrm{s}$, is possible because the simulations were performed with only the flow released by the power plant located upstream in the river, as explained in Ref. [8].

Figure 11 shows the variation of charge states of the reservoir formed by the Laranjeiras dam and operated for energy storage. The variation of the states of charge throughout the year can be observed. The water reservoir is almost empty near the period of less water availability, a little earlier than the period of less solar energy availability, and the reservoir ends the year completely full. The energy resources have little complementarity and the periods of maximum availability also coincide approximately in time.

\section{Conclusions}

This paper presents the main results of a pre-feasibility study of a hydroelectric photovoltaic hybrid system for the repowering of the Laranjeiras dam, in southern Brazil, considering the use of the reservoir formed by the dam for energy storage. The optimum solution obtained with Homer includes a hydroelectric power plant generating $1497 \mathrm{~kW}$ installed at the base of the dam, operating in conjunction with $360 \mathrm{~kW}$ PV modules, operating over floating structures on the

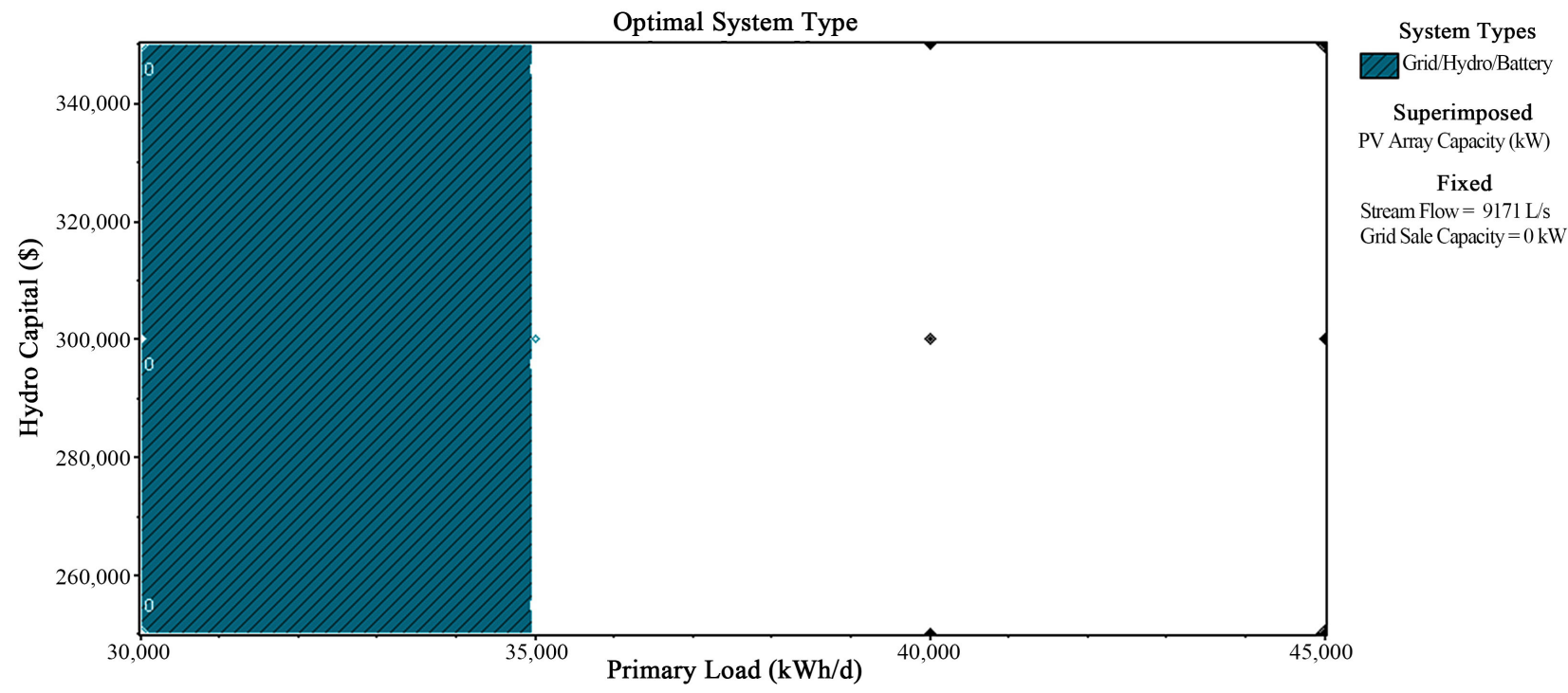

Figure 8. Optimization space for the capital cost of the hydroelectric power plant $[\mathrm{US} \$ / \mathrm{kW}]$ as a function of the consumers demand per day $[\mathrm{kWh} / \mathrm{d}]$, with the PV power superimposed on the graph, without connection to the grid, for a stream flow rate of $9171 \mathrm{~L} / \mathrm{s}$. 


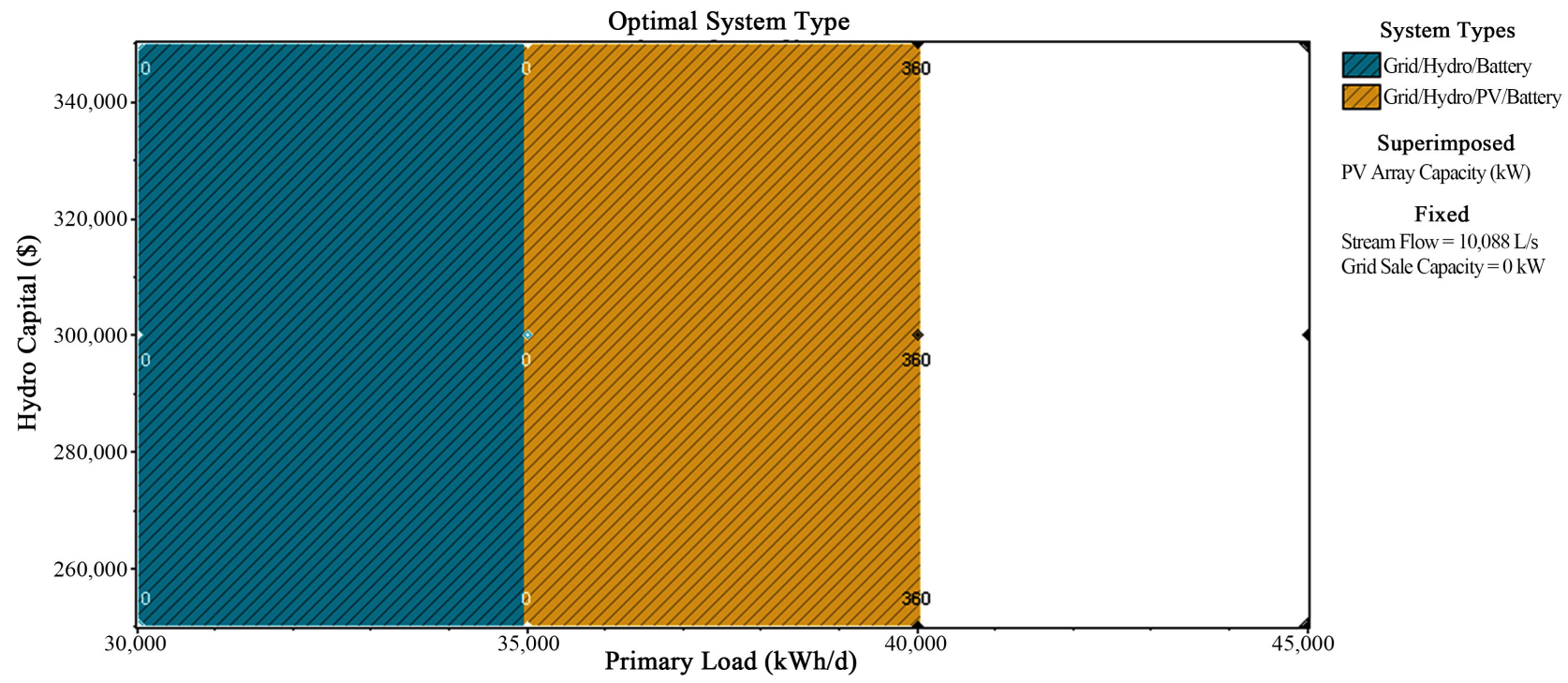

Figure 9. Optimization space for the capital cost of the hydroelectric power plant $[\mathrm{US} \$ / \mathrm{kW}]$ as a function of the consumer loads demand per day $[\mathrm{kWh} / \mathrm{d}]$, with the PV power superimposed on the graph, without connection to the grid, for a stream flow rate of $10,088 \mathrm{~L} / \mathrm{s}$.

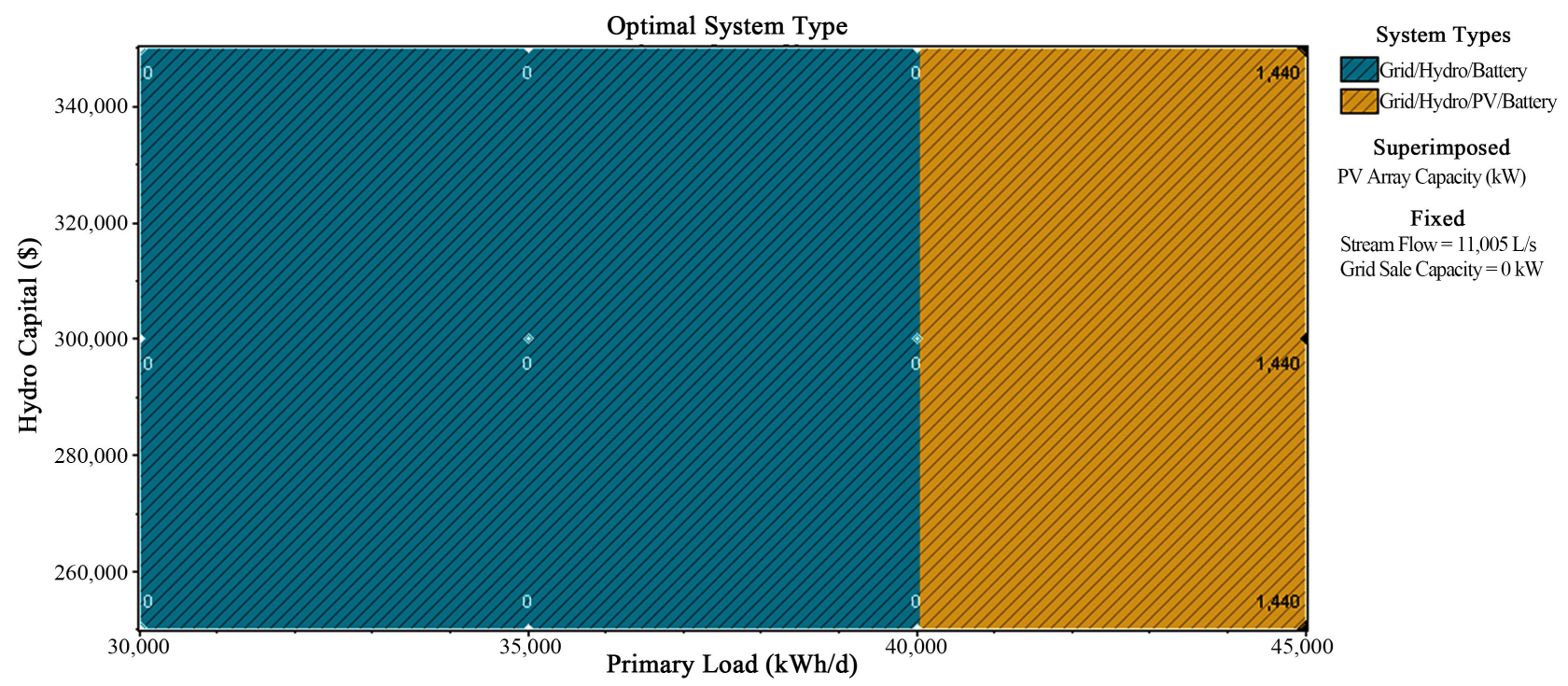

Figure 10. Optimization space for the capital cost of the hydroelectric power plant [US $\$ / \mathrm{kW}$ ] as a function of the consumer loads demand per day $[\mathrm{kWh} / \mathrm{d}]$, with the PV power superimposed on the graph, without connection to the grid, for a stream flow rate of $11,005 \mathrm{~L} / \mathrm{s}$.

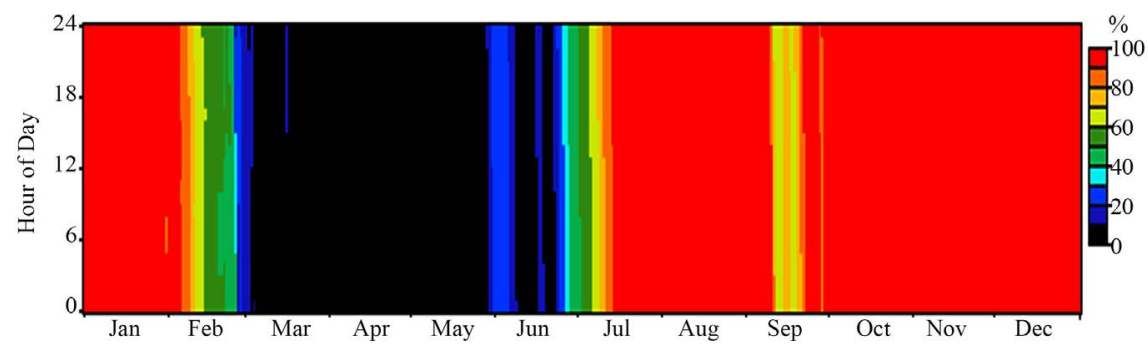

Figure 11. State of charge of the reservoir formed by the Laranjeiras Dam for the solution of Figure 7 and which is part of the optimization space of Figure 9. 
surface of the water reservoir. This system was simulated with the possibility of buying $200 \mathrm{~kW}$ and not selling surplus energy for the grid, supplying $40 \mathrm{MWh}$ per day, with a capital cost of US\$3,285,617 per $\mathrm{kW}$ and a cost of energy of US\$0.021 per kWh.

The comparison of the results of this paper with the results previously presented by Vasco et al. [8], which studied the design of this hybrid system without the use of the reservoir for energy storage, indicated some benefits of the reservoir in the operation of the hybrid system. Energy storage allowed raising the power of the PV modules from $180 \mathrm{~kW}$ to $360 \mathrm{~kW}$ and also increasing the penetration of renewable energy in the system from $90 \%$ to $99 \%$. The energy storage also allowed reducing the total net present cost from US $\$ 3,984,885$ to US $\$ 3,285,617$ and the cost of energy from US $\$ 0.026$ per $\mathrm{kWh}$ to US $\$ 0.021$ per $\mathrm{kWh}$. Feasibility of the optimal solution with a higher average stream flow rate contributed to these results, both technically and financially.

\section{Acknowledgements}

This work was developed as a part of the activities of the Research Group on Renewable Energies and Sustainability of the Instituto de Pesquisas Hidráulicas, Universidade Federal do Rio Grande do Sul, in southern Brazil. The authors acknowledge the support received by the institution. The first author is grateful for the support received from the Post-Graduation Students Program (PEC-PG), from CAPES/CNPq/MRE-Brasil. The fourth author acknowledges the financial support received from CNPq for his research work (proc. n.312941/2017-0).

\section{Conflicts of Interest}

The authors declare no conflicts of interest regarding the publication of this paper.

\section{References}

[1] Faias, S., Sousa, J. and Castro, R. (2009) Embedded Energy Storage Systems in the Power Grid for Renewable Energy Sources Integration. In: Hammons, T.J., Ed., Renewable Energy, In Tech, Rijeka, 63-88. https://doi.org/10.5772/7376

[2] Castronuovo, E.D. and Usaola, J. (2013) Coordination between Wind Farms and Storage Devices, Technical and Economic Aspects. In: Pardalos, P.M., et al., Eds., Handbook of Wind Power Systems, Springer, Berlin, Heidelberg, 591-622. https://doi.org/10.1007/978-3-642-41080-2_17

[3] Canales, F.A., Beluco, A. and Mendes, C.A.B. (2015) A Comparative Study of a Wind Hydro Hybrid System with Water Storage Capacity: Conventional Reservoir or Pumped Storage Plant? Journal of Energy Storage, 4, 96-105. https://doi.org/10.1016/j.est.2015.09.007

[4] Lambert, T.W., Gilman, P. and Lilienthal, P.D. (2005) Micropower System Modeling with Homer. In: Farret, F.A. and Simões, M.G., Eds., Integration of Alternative Sources of Energy, John Wiley \& Sons, Hoboken, 379-418. https://doi.org/10.1002/0471755621.ch15

[5] Lilienthal, P.D., Lambert, T.W. and Gilman, P. (2004) Computer Modeling of Re- 
newable Power Systems. In: Cleveland, C.J., Ed., Encyclopedia of Energy, Elsevier, Amsterdam, Vol. 1, 633-647. https://doi.org/10.1016/B0-12-176480-X/00522-2

[6] Canales, F.A., Beluco, A. and Mendes, C.A.B. (2017) Modelling a Hydropower Plant with Reservoir with the Micro Power Optimization Model (HOMER). International Journal of Sustainable Energy, 36, 654-667. https://doi.org/10.1080/14786451.2015.1080706

[7] Canales, F.A. and Beluco, A. (2014) Modeling Pumped Hydro Storage with the Micro Power Optimization Model (HOMER). Journal of Renewable and Sustainable Energy, 6, Article ID: 043131. https://doi.org/10.1063/1.4893077

[8] Vasco, G., Silva, J.S., Beluco, A., Rossini, E.G. and Souza, J. (2018) A Hydro PV Hybrid System as a New Concept for an Abandoned Dam in Southern Brazil. Computational Water Energy and Environmental Engineering, 8, 41-56.

https://doi.org/10.4236/cweee.2019.82003

[9] Yüksel, I. (2010) Hydropower for Sustainable Water and Energy Development. Renewable and Sustainable Energy Reviews, 14, 462-469. https://doi.org/10.1016/j.rser.2009.07.025

[10] Zhang, X., Li, H.Y., Deng, Z.D., Ringler, C., Gao, Y., Hejazi, M.I. and Leung, L.R. (2018) Impacts of Climate Change, Policy and Water-Energy-Food Nexus on Hydropower Development. Renewable Energy, 116, 827-834. https://doi.org/10.1016/j.renene.2017.10.030

[11] Ferrer-Gisbert, C.M., Ferran-Gozalvez, J.J., Santafe, M.R., Ferrer-Gisbert, P., Sanchez-Romero, F.J. and Torregrose-Soler, J.B. (2013) A New Photovoltaic Floating Cover System for Water Reservoirs. Renewable Energy, 60, 63-70. https://doi.org/10.1016/j.renene.2013.04.007

[12] Vision Battery (2018) Vision 6FM200D Model. http://www.vision-batt.com

[13] Connolly, D., Lund, H., Mathiesen, B.V. and Leahy, M. (2010) A Review of Computer Tools for Analyzing the Integration of Renewable Energy into Various Energy Systems. Applied Energy, 87, 1059-1082. https://doi.org/10.1016/j.apenergy.2009.09.026

[14] HomerEnergy (2018) Software Homer, Version 2.68 Beta, Legacy. http://www.homerenergy.com

[15] IRENA International Renewable Energy Agency (2011) Renewable Energy Technologies: Cost Analysis Series, Hydropower.

http://www.irena.org/documentdownloads/publications/re_technologies_cost_anal ysis-hydropower.pdf

[16] Braciani, U. (2011) Cost Structure for Implementation of Power Generation Plants in Brazil. Graduationwork, Faculdade de Economia, Universidade Federal de Santa Catarina, Florianópolis. (In Portuguese)

[17] Schultz, R., Beluco, A., Homrich, R.P. and Eifler, R.C. (2016) A PV Hydro Hybrid System Using Residual Flow of Guarita Hydro Power Plant, in Southern Brazil. In: Kishor, N. and Fraile-Ardanuy, J., Eds., Modeling and Dynamic Behavior of $\mathrm{Hy}$ dropower Plants, The Institution of Engineering and Technology, 185-202. 